\title{
DESENVOLVIMENTO DA QUALIDADE HOSPITALAR POR MEIO DA DEMANDA DA OUVIDORIA
}

\author{
Daiany Freitas Chaves ${ }^{1}$ \\ Fabiana Gomes Barbosa² \\ Juliana Silva Nascimento Menezes ${ }^{3}$
}

\begin{abstract}
Resumo
A Ouvidoria ganha evidência e seriedade no mercado por prover as instituições com relevantes informações a respeito dos clientes e dos serviços ofertados. As informações oriundas da Ouvidoria devem ser um caminho efetivo na busca da qualidade dos serviços, contribuindo para um melhor planejamento da assistência prestada e promoção do cuidado humanizado, atendendo assim às expectativas dos clientes. E, como serviço de escuta, deve estreitar a relação entre os clientes e o hospital, visando garantir eficiência e transparência em suas relações. Este artigo aborda o tema "Desenvolvimento da Qualidade" a partir das experiências do Serviço de Ouvidoria do Hospital São Camilo e São Luís - HSCSL. Neste estudo objetivou-se demonstrar a evolução da qualidade nos serviços de saúde; discutir a Ouvidoria no ambiente hospitalar e a importância do serviço como canal de comunicação do cliente. O procedimento metodológico teve abordagem de pesquisa quantitativa e análise documental. Para coleta de dados foram analisadas 3.459 manifestações registradas na Ouvidoria no período de 2014 a 2017. Os resultados revelam que o quantitativo de manifestações foi maior nos serviços: internação, enfermagem e médico, todos relacionados ao tempo de espera para o atendimento.
\end{abstract}

Palavras-chave: Ouvidoria. Qualidade. Serviços. Eficiência.

1 Auxiliar Administrativa do Serviço de Ouvidoria do Hospital São Camilo e São Luís. (ouvidoria@saocamilomacapa.org.br) (96 3312-2435)

2 Tecnóloga em Gestão Hospitalar. Gerente de Atendimento do Hospital São Camilo e São Luís. (ger.ambulatorios@saocamilomacapa.org.br) (96 3312-2455)

3 Mestra em Gestão de Empresas. Especialista em Gestão. Especialista em Gestão de Projetos Sociais. Graduação em Serviço Social. Gerente da Qualidade do Hospital São Camilo e São Luís. (ger.qualidade@saocamilomacapa.org.br) (96 3312-2439) 


\begin{abstract}
The Ombudsman receives evidence and seriousness in the market for providing the institutions with relevant information regarding the clients and the services offered. Information from the Ombudsman's Office should be an effective way to seek the quality of services, contributing to a better planning of the care provided and promotion of humanized care, thus meeting clients' expectations. And, as a listening service, the relationship between clients and the hospital should be strengthened in order to ensure efficiency and transparency in their relationships. This article addresses the theme of "Quality Development" based on the experience of the Ombudsman Service of Hospital São Camilo and São Luís - HSCSL. The objective of this study was to demonstrate the evolution of quality in health services; discuss the Ombudsman's Office in the hospital environment and the importance of the service as the client's communication channel. The methodological procedure had an approach of quantitative research and documentary analysis. For the collection of data, 3,459 manifestations registered at the Ombudsman's Office from 2014 to 2017 were analyzed. The results reveal that the number of manifestations was higher in the services: hospitalization, nursing and physician, all related to waiting time for care.
\end{abstract}

Keywords: Ombudsman. Quality. Services. Efficiency. 


\section{INTRODUÇÃO}

A área hospitalar está se tornando competitiva pelas transformações que estão ocorrendo no meio empresarial, exigindo uma nova estrutura organizacional, com a inclusão de novos conceitos que tornem os processos mais eficientes e seguros, possibilitando assim atingir melhores resultados. A gestão de uma unidade hospitalar traz muitos desafios inerentes a uma área tão complexa quanto a da prestação de serviços a seres humanos com um amplo espectro de necessidades e anseios.

O cenário de insatisfação associado à má qualidade na prestação de serviços instigou a criação de um padrão de qualidade, processo definido como um conjunto de atributos que inclui nível de excelência profissional, uso eficiente de recursos, mínimo de risco ao usuário, alto grau de aceitação por parte dos clientes e efeito favorável na saúde.

Com a introdução dos programas de Gestão da Qualidade e a busca da certificação hospitalar, verificou-se a necessidade da implantação de um canal de escuta do cliente, haja vista a quantidade de manifestações expressas e que permitem a melhoria contínua dos processos. As instituições de saúde, ao utilizarem essas informações, podem descobrir como os clientes se sentem e por que agem de uma determinada maneira.

A necessidade de avaliar a percepção de satisfação dos clientes para com a qualidade no atendimento prestado está se consolidando entre os administradores hospitalares como resultado de grandes transformações no cenário de atuação das organizações de saúde. Dessa forma, analisar o índice de satisfação dos clientes com os serviços de saúde é relevante, haja vista que atualmente os hospitais buscam atender seus clientes com total qualidade.

Nesse contexto, a implantação do serviço de Ouvidoria constitui-se num instrumento para a melhoria dos serviços ofertados, pois favorece a avaliação e o aprimoramento das atividades da organização.

Diante disso, espera-se que os resultados apresentados neste artigo possam contribuir para o avanço das discussões e novas perspectivas sobre a Ouvidoria como instrumento imprescindível para o processo de melhoria contínua da qualidade dos serviços de saúde.

\section{QUALIDADE NOS SERVIÇOS DE SAÚDE}

Para NOGUEIRA (2008), a literatura sobre a qualidade do atendimento nos sistemas de saúde é muito extensa e, ao mesmo tempo, difícil de sistematizar. Dependendo do paradigma disciplinar, qualidade pode ser entendida de diversas maneiras, usando termos diferentes, etiquetas e modelos.

A mesma autora cita que os autores do Institute of Medicine - IOM revisaram mais de cem definições sobre qualidade dos cuidados de acordo com dezoito dimensões. Com base nessa revisão, chegaram à definição de qualidade do atendimento como sendo o grau em que os serviços de saúde para os indivíduos aumenta a probabilidade de obter resultados desejados e consistentes com o conhecimento profissional atual.

Nos últimos anos, percebem-se importantes modificações na área de saúde no que se refere à necessidade de alcançar maior competitividade e conquistar novos mercados. 
No mercado atual extremamente competitivo, associado a um cenário econômico nebuloso e a uma grande regulamentação do setor saúde, com a crescente imposição de demonstração de eficácia/eficiência médico-hospitalar, a implantação de mecanismos de gestão eficientes que garantam a viabilização do setor se faz urgente e necessária. (COUTO; PEDROSA, 2007, p. 9)

Segundo MANZO (2009), a preocupação com a garantia da segurança do atendimento e a necessidade de atender às expectativas e aos direitos dos clientes são alguns dos aspectos que exigem das instituições uma mudança na forma de gerir a saúde, inovando e oferecendo serviços com qualidade.

De acordo com GODOI (2008), a qualidade nos serviços envolve uma correta adequação de todos os serviços prestados às necessidades que o paciente apresenta, superando suas expectativas.

Para avaliar a qualidade dos serviços das Instituições de Saúde, foi constituída em 1999 a instituição privada Organização Nacional de Acreditação - ONA, para coordenar e gerir o Sistema Brasileiro de Acreditação - SBA e também para incentivar o setor de saúde a aprimorar seus processos de gestão e qualidade da assistência.

O processo de Acreditação é uma ferramenta desenvolvida para auxiliar as organizações a avaliar seus processos e a identificar onde são necessárias melhorias. É também uma abordagem objetiva, mensurável e de aplicação fácil e coerente. (ONA, 2018, p. 27)

As seções são compostas por três níveis de complexidade crescente e com princípios específicos:

- Nível 1 - Acreditado - Princípio Segurança: as exigências deste nível contemplam o atendimento aos requisitos de segurança e qualidade na assistência prestada ao cliente, nas especialidades e nos serviços da organização de saúde a ser avaliada, com os recursos humanos compatíveis com a complexidade, qualificação adequada do profissional e responsável técnico com habilitação correspondente para as áreas de atuação institucional.

- Nível 2 - Acreditado Pleno - Princípio Gestão Integrada: as exigências deste nível contemplam evidências de interação entre os processos bem como o acompanhamento e a avaliação dos seus resultados, alinhando as estratégias definidas, promovendo ações de melhoria.

- Nível 3 - Acreditado com Excelência - Princípio Excelência em Gestão: as exigências deste nível contemplam evidências de uma gestão em excelência, utilizando o conhecimento e o aprendizado para a tomada de decisão, bem como o relacionamento com todas as partes interessadas, buscando melhores resultados, a sustentabilidade e a responsabilidade socioambiental, promovendo ciclos de melhoria. (ONA, 2018, p. 27)

\section{OUVIDORIA NO AMBIENTE HOSPITALAR}

No hospital, as solicitações, reclamações e sugestões dos pacientes são tratadas pelo Serviço de Ouvidoria, que as recebe pessoalmente, por e-mail ou por telefone. Após o registro documental da ocorrência, em sistema informatizado, são comunicados os gestores 
dos setores pertinentes, que avaliarão, verificarão os fatos e necessariamente informarão das ações que estão sendo tomadas. Com a finalização da ocorrência dentro dos setores envolvidos, o Serviço de Ouvidoria entra em contato com o paciente, se for o caso, para confirmação de resposta e encerramento da ocorrência. (BURMESTER, 2009, p. 410)

As Ouvidorias hospitalares foram implantadas como uma das formas pelas quais os hospitais podiam auscultar os "dizeres" sobre a qualidade de seu atendimento. Constituíam-se, portanto, em modelos institucionais para averiguar suas falhas, as quais apontavam problemas estruturais e de funcionamento.

Segundo CANCLINI (2010, p.59), "a chave para atingir os objetivos da organização consiste em determinar as necessidades e os desejos dos consumidores-alvo e satisfazê-los mais eficaz e eficientemente do que os concorrentes".

Hoje em dia, trabalha-se para que o indivíduo, através do interesse particular, atue como agente participativo no crescimento e desenvolvimento dos serviços, não apenas denunciando mas também sugerindo, dessa forma consolidando a imagem das instituições como a de prestadoras de serviços atuantes e eficientes.

Para LUONGO (2011), as críticas deixadas pelos clientes devem ser analisadas de modo a que sejam encontradas soluções para os problemas. Os gerentes de cada área ou os responsáveis pela atividade falha devem encontrar as causas e os fatores que levaram ao descontentamento do cliente e trabalhar medidas/ações de melhoria.

ALVES JÚNIOR (2004) cita que as instituições devem ter maturidade para corrigir e aperfeiçoar por iniciativa própria os processos e resultados frágeis apontados pela clientela. Dessa forma, a Ouvidoria constitui-se como um serviço complementar no processo de identificação das necessidades e anseios dos clientes em relação aos serviços prestados pelos estabelecimentos de saúde.

\section{SERVIÇO DE OUVIDORIA DO HOSPITAL SÃO CAMILO E SÃO LUÍS}

O Serviço de Ouvidoria é de suma importância para instituições públicas ou privadas no que tange à busca pela qualidade no atendimento, bem como nos serviços prestados aos clientes. Tem por objetivo principal trabalhar ações com base nas oportunidades de melhorias identificadas, uma vez que recebe diversas reclamações do público diverso que a procura.

O feedback do cliente significa o processo pelo qual a instituição recebe informações vindas do público. Essas informações podem resultar de pesquisas, contatos com o serviço de atendimento do cliente (SAC), reclamações verbais ou escritas, sugestões, elogios e satisfações. (LUONGO et al., p. 182, 2011)

O Serviço de Ouvidoria fundamenta-se em um espaço para acolher, tratar e encaminhar as manifestações dos clientes/pacientes aos gerentes, como também trabalha em uma perspectiva informativa, buscando maior eficácia nos atendimentos prestados.

Uma das ações do Serviço de Ouvidoria é a realização de pesquisas com o objetivo de conhecer 
a realidade e a satisfação dos pacientes internados, assim como daqueles que procuram os serviços para atendimentos ambulatoriais, pronto atendimento e diagnóstico. As pesquisas podem subsidiar o Hospital na reformulação e avaliação das suas políticas institucionais e protocolos utilizados.

O Hospital de Macapá elaborou em 2011 um projeto para implantação do Serviço de Ouvidoria. Em 2012 iniciaram-se os primeiros atendimentos, e a existência do serviço foi sendo divulgada para os clientes no momento da aplicação da pesquisa de satisfação realizada pelo Serviço Social e pelos Gerentes de Atendimentos.

O quadro funcional da Ouvidoria é composto por três assistentes sociais (uma ocupa a gerência do serviço), dois aprendizes, responsáveis pela aplicação da pesquisa de satisfação, e um auxiliar administrativo, responsável pelo recebimento das manifestações dos clientes, tais como denúncias, reclamações, informações, elogios, solicitações e sugestões referentes aos serviços oferecidos pelo hospital.

\subsection{Como Funciona o Serviço de Ouvidoria}

- Recebe as manifestações dos clientes, tais como denúncias, reclamações, informações, elogios, solicitações e sugestões referentes aos serviços prestados e encaminha aos setores competentes.

- Fornece informações gerais sobre o funcionamento do hospital, os direitos e deveres dos clientes.

- Identifica e avalia o grau de satisfação dos clientes em relação aos serviços prestados, através da pesquisa de satisfação.

- Realiza a mediação de situações emergenciais atenuando os conflitos.

- Divulga relatórios gerenciais para subsidiar o perfil social e auxiliar na tomada de decisão para implementação de melhorias.

- Realiza visita nas clínicas (busca ativa), antecipando assim as possíveis insatisfações dos clientes no que se refere à estrutura, equipamentos, atendimento das equipes e pendências de exames e avaliações, assim como outras demandas pertinentes ao atendimento.

\section{METODOLOGIA}

\subsection{Tipo de Pesquisa}

Segundo GIL (1999, p. 27), "para que um conhecimento possa ser considerado científico, torna-se necessário identificar as operações mentais e técnicas que possibilitam sua verificação. Ou, em outras palavras, determinar o método que possibilitou chegar a esse conhecimento".

Esse mesmo autor enfatiza ainda que se pode definir método como caminho para se chegar a determinado fim. E método científico como o conjunto de procedimentos intelectuais e técnicos adotados para se atingir o conhecimento. 
Para a realização deste estudo foram utilizadas a pesquisa quantitativa e a análise documental. A abordagem quantitativa é uma classificação do método científico que utiliza diferentes técnicas estatísticas para quantificar opiniões e informações para um determinado estudo. Na pesquisa quantitativa o objetivo é medir informações. Dessa forma, os dados coletados apresentam uma natureza mais estatística, sendo os resultados expostos em forma de gráficos, tabelas etc.

Segundo GODOI (2008), a análise documental deve ser feita quando o pesquisador necessita identificar informações factuais em documentos, a partir de questões que sejam do interesse da pesquisa. Sua utilização ocorre quando o acesso aos dados é problemático, quando se pretende ratificar informações e quando interessa investigar a expressão do sujeito.

\subsection{Cenário da Pesquisa}

Segundo PESSINI e GIANELLA JR. (2012), a história do HSCSL é a concretização do sonho missionário do ex-industrial italiano Marcello Candia. Nascido em Milão em 1916, numa família de muitas posses, Marcello, desde muito jovem, sempre acalentou o desejo de ajudar os mais necessitados, onde eles estivessem.

O Dr. Marcello Candia ganhou da administração do Território do Amapá um local onde poderia começar as obras do hospital. Em 1960, iniciou-se a construção, com os recursos enviados da Itália por ele. A obra, porém, avançou lentamente, concretizando-se depois de 9 anos. Em 7 de fevereiro de 1969, o hospital foi inaugurado e começou a funcionar apenas com atendimento ambulatorial. Diante de muitas dificuldades financeiras, em março de 1972, o Dr. Marcello Candia pediu auxílio para uma congregação de padres para administrar o hospital.

Em 1974, o Dr. Marcello doou o hospital a uma instituição religiosa filantrópica, coordenada por padres cuja sede no Brasil é situada em São Paulo.

Atualmente possui duzentos leitos - sendo classificado como hospital de grande porte -, incluindo vinte leitos de UTI Adulto e nove de UTI Neonatal. Credenciado junto ao SUS, o hospital, considerado de referência no Estado, realiza atendimento nas especialidades de média e alta complexidade.

Seu quadro funcional é de 1.014 colaboradores e 340 médicos.

Em 2012, o hospital foi acreditado em nível de segurança, atingindo êxito em todas as etapas do processo de acreditação. Em 2016, foi acreditado pleno em nível de gestão integrada demonstrando a interação de seus processos, bem como acompanhamento e avaliação dos resultados e promoção de ações de melhoria.

\subsection{Coleta de Dados}

Para a realização deste estudo foram utilizadas a pesquisa quantitativa e a análise documental. Na abordagem quantitativa foram analisados os tipos de manifestações que chegaram à Ouvidoria no período de 2014 a 2017. Para a análise documental, foi necessária a utilização dos 
relatórios, incluindo o manejo de informações e materiais a partir das demandas dos usuários contidas em registro no Serviço de Ouvidoria, computando um total de 3.459 manifestações (recebidas por e-mail, telefone e pessoalmente).

Os dados coletados foram analisados considerando a natureza das manifestações, o levantamento de subsídios para qualificar o funcionamento da Ouvidoria como ferramenta de gestão e a proposição de ações para o aprimoramento do desenvolvimento da qualidade hospitalar. Em seguida, os dados foram catalogados e ordenados em um banco eletrônico no programa do Microsoft Office Excel (versão 14.0, 2010) e analisados por meio de estatística descritiva. Foram utilizadas as variáveis quantitativas de percentual e número relativo para discutir o assunto e os resultados obtidos, que foram apresentados em forma de gráficos.

\section{RESULTADOS}

\section{GRÁFICO 1 - Pesquisa de Satisfação do Cliente Externo}

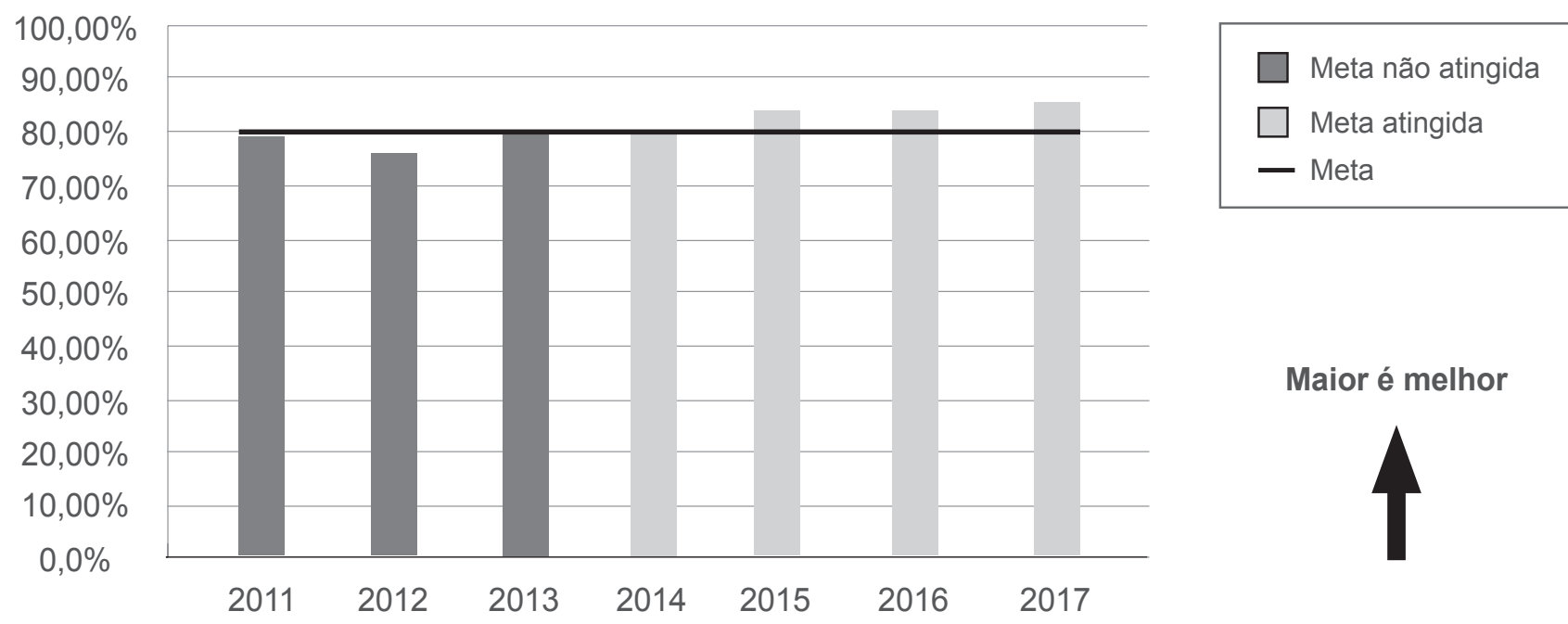

Fonte: Recursos Humanos

Segundo KOTLER (1996, p. 46), "a chave para atingir os objetivos da organização consiste em determinar as necessidades e os desejos dos consumidores-alvo e satisfazê-los mais eficaz e eficientemente do que os concorrentes". No caso da instituição de saúde o diferencial é o atendimento com qualidade ao longo de todo processo de prestação de serviço.

Para os pacientes internados é realizada a pesquisa pelos aprendizes dos Serviços de Ouvidoria e Internação através do formulário para avaliação da estadia e atendimento. Todos os dados de avaliação da satisfação irão compor base de dados informatizada de onde serão extraídas estatísticas estratificadas por setor, período, tipo de atendimento e outros. 
Segundo informações do Serviço de Ouvidoria, no período de 2011 a 2013, o índice de insatisfação se deu em razão da fragilidade no agendamento de consultas dos ambulatórios, demora no atendimento das equipes, clareza nas informações etc.

Mediante as imensas dificuldades que o setor saúde enfrenta, torna-se importante buscar profissionalizar o sistema de gestão dos hospitais. O HSCSL busca desenvolver e oferecer serviços de qualidade há vários anos. A gestão atual voltou a exercer suas atividades aproximadamente há quatro anos, sendo observado um aumento gradativo da satisfação dos clientes no período de 2014 a 2017, graças à implantação de ações de melhoria no que diz respeito à reestruturação da central telefônica, treinamento referente a atendimento ao cliente e comunicação, infraestrutura, instalações de novos serviços etc. A alta administração acredita na metodologia da ONA por oferecer transparência, valorizar os clientes, apostar na padronização e monitoramento de processos internos e na interação entre fornecedores e clientes. A implantação do processo de qualidade vem se somar aos interesses da instituição, garantindo um crescimento a passos seguros, com planejamento, prioridade muito bem definida e a transparência que sempre lhe foi peculiar.

\section{GRÁFICO 2 - Serviço de Ouvidoria}

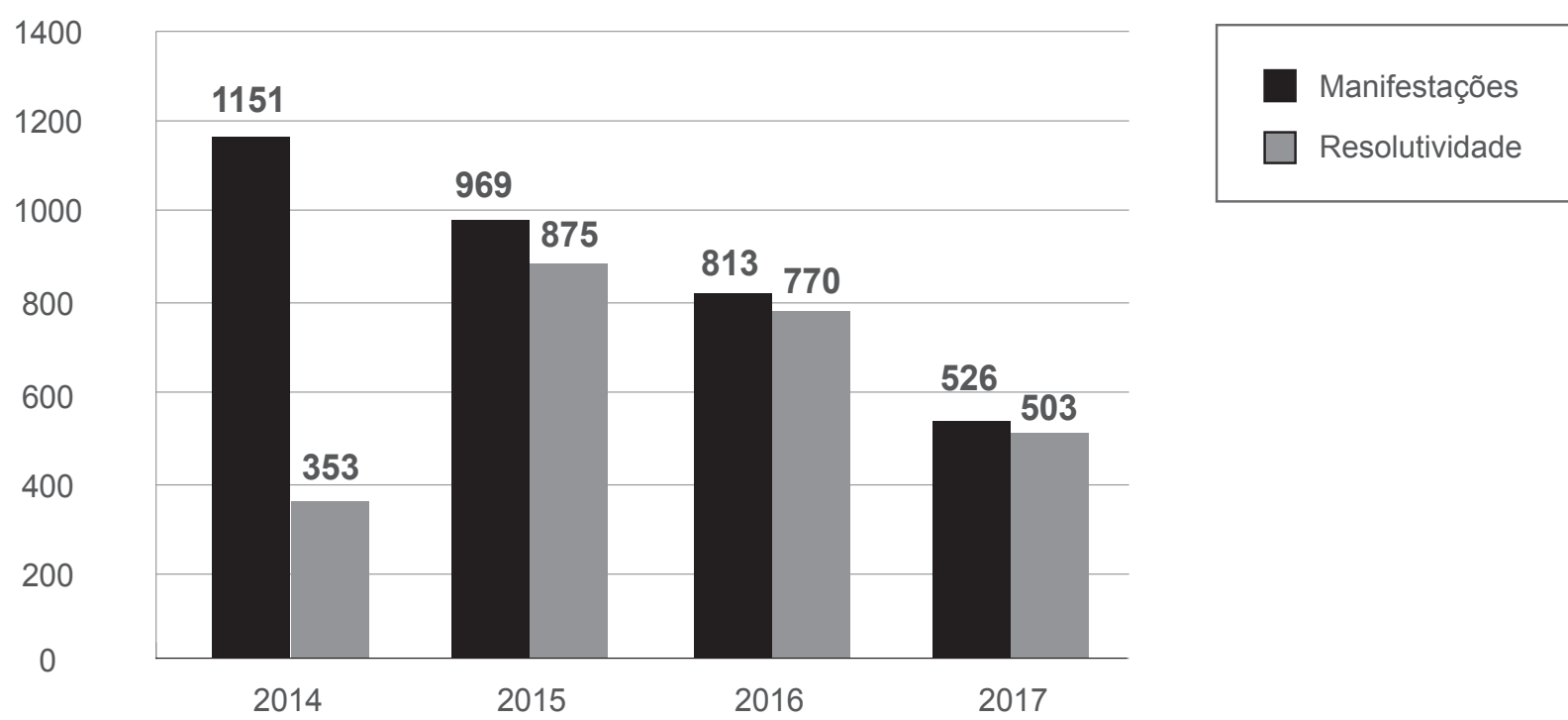

A pesquisa de satisfação deixou de ser a única ferramenta de comunicação e escuta do cliente. Com a implantação da Ouvidoria, a avaliação da qualidade dos serviços prestados tornou-se diária. O Gráfico 2 demonstra o quantitativo de manifestações e resolutividade recebidas pela Ouvidoria do Hospital por ano.

O feedback do atendimento pela visão do cliente possibilita à instituição executar ações corretivas e, posteriormente, ações preventivas para que os mesmos problemas não voltem a acontecer, como dito. (LUONGO, p. 183, 2011) 
Assim, ao receber reclamação ou informação da existência de um problema, a Ouvidoria deve definir prazo para solucioná-lo, estabelecer plano de ação para investigar a causa, produzir relatórios gerenciais que subsidiem os atores na tomada de decisões, realizar a análise de dados estatísticos para mensurar o tempo e a extensão do problema.

O feedback da Ouvidoria do hospital ao cliente tem prazo de 7 a 10 dias úteis, porém as situações consideradas emergenciais são priorizadas e resolvidas imediatamente. As situações consideradas mais simples e de fácil resolução também são encaminhadas rapidamente para pronta resposta ao cliente. Esta prática contribui para a credibilidade e está alinhada aos objetivos estratégicos da instituição.

O Gráfico 2 demonstra a série histórica, no qual observamos que, a partir de 2015, o resultado foi bastante positivo no que se refere à resolutividade das manifestações relatadas pelos clientes.

Cabe destacar que a ação foi fortalecida pela estratégia de implantação de busca ativa (visita às clínicas), que permitiu ao Serviço de Ouvidoria antecipar-se às possíveis insatisfações dos clientes no que se refere a estrutura, equipamentos, atendimento das equipes e pendências de exames e avaliações.

\section{GRÁFICO 3 - Manifestação - Pacientes Internados}

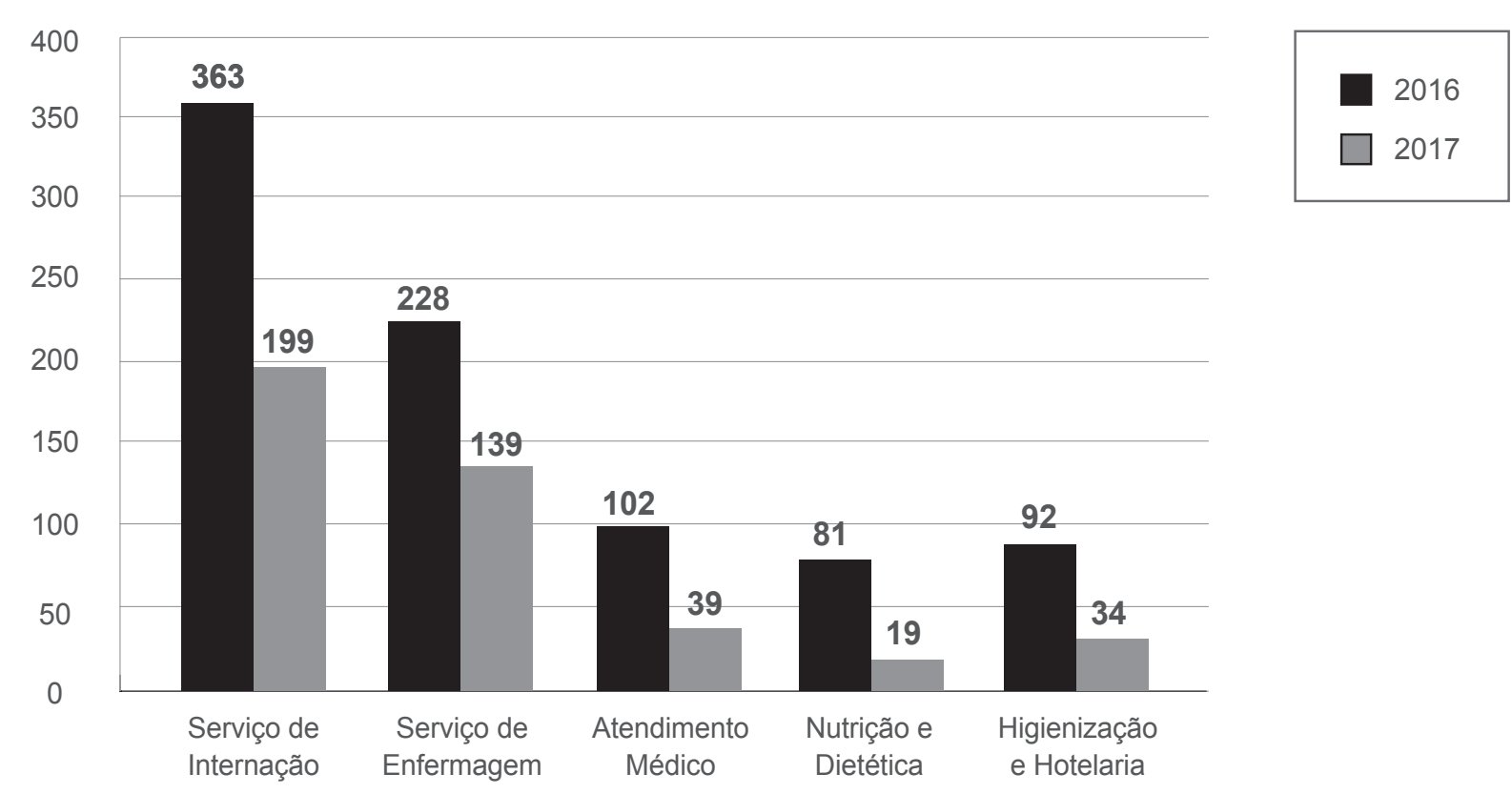

Fonte: Serviço de Ouvidoria

De acordo com o Gráfico 3, no ano de 2016 o quantitativo de manifestações foi maior nos serviços: internação, enfermagem e médico. Das 866 manifestações, 36,95\% (320) estão relacionados ao tempo de espera para o atendimento em todos os serviços. 
Com isso, no ano seguinte foram fortalecidas as ações voltadas ao tempo de atendimento dos serviços, conduzidas pelo Setor de Recursos Humanos através de diversos treinamentos, como: café com desenvolvimento - atendimento ao cliente hospitalar (orientação, comunicação e humanização do cliente), ética nas relações profissionais, comunicação interpessoal, comunicação assertiva, atendimento humanizado, abordagem ao paciente, entre outros. Ainda cabe destaque a contratação de dois profissionais (Assistente Social e Psicólogo) para a realização de abordagem psicossocial no serviço de pronto atendimento e demais unidades, visando acolher e orientar os clientes e intermediar conflitos quando necessário, otimizando o fluxo e o tempo de permanência dos clientes.

Logo foram conduzidas ações no plano organizacional, com o redesenho de todos os processos, o redesenho da cadeia medicamentosa, o emponderamento do gestor clínico, o desenvolvimento das lideranças, bem como o envolvimento de toda a equipe assistencial e administrativa na melhoria dos processos.

Após as ações supracitadas, observa-se a diminuição das manifestações em relação a esses serviços no ano subsequente, revelando assim a melhoria contínua no seguimento dos serviços prestados, bem como na qualidade das orientações, comunicação e humanização do cliente.

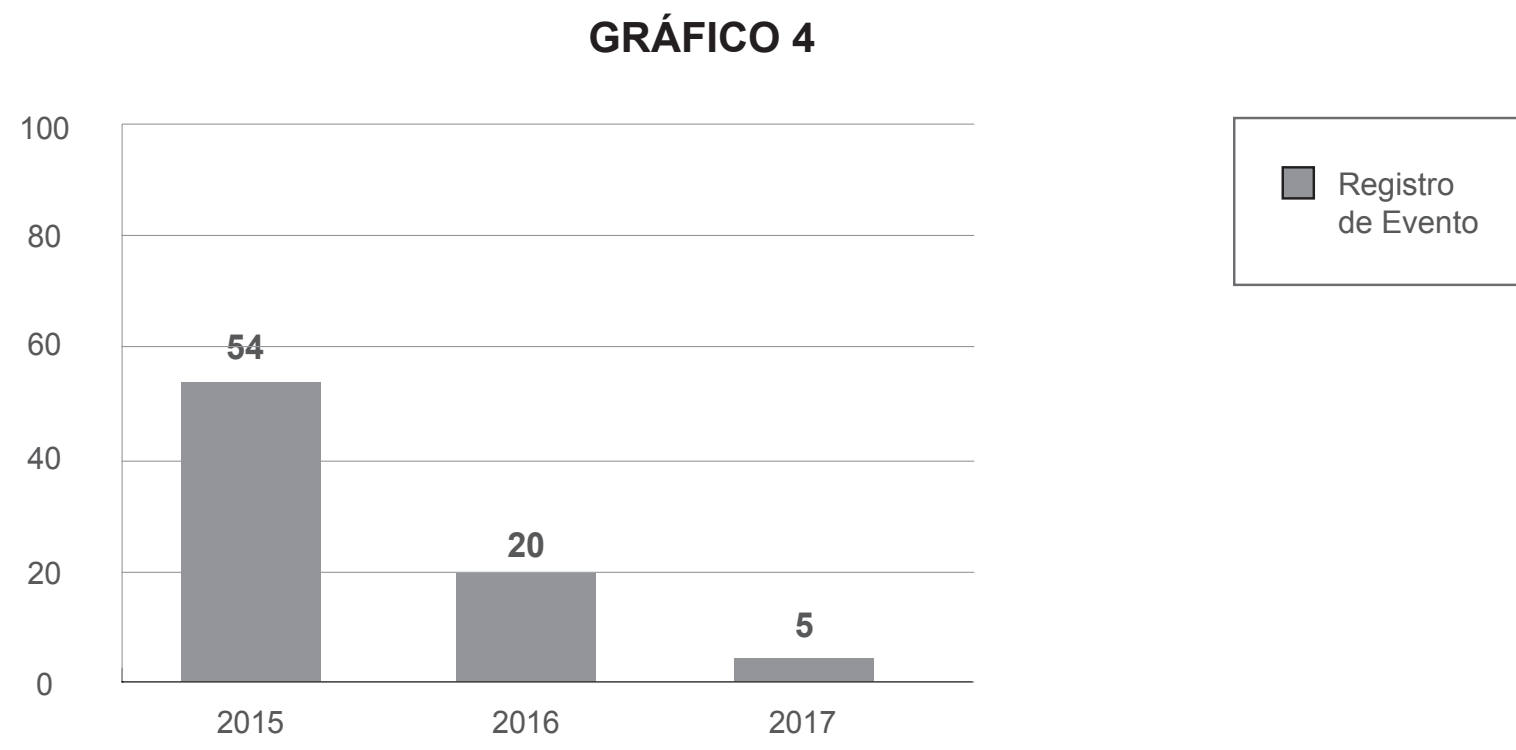

Fonte: Setor de Qualidade

No período de 2015 a 2017, foram formalizadas 2.308 reclamações. A partir de 79 dessas reclamações foram geradas notificações de evento ao Setor da Qualidade pelo Serviço de Ouvidoria. As notificações cadastradas foram classificadas como: ocorrência comunicável, quase erro e incidentes sem dano relacionados à assistência ao paciente, e durante o acompanhamento pelo Setor da Qualidade observou-se que o desfecho final se deu favorável para $100 \%$ dos pacientes envolvidos nas notificações geradas pelo Serviço de Ouvidoria. 


\section{CONSIDERAÇÕES}

As informações oriundas da Ouvidoria devem ser um caminho efetivo na busca da qualidade dos serviços, contribuindo para melhor planejamento da assistência prestada e promoção do cuidado humanizado, atendendo assim às expectativas dos clientes. E, como serviço de escuta, deve estreitar a relação entre os clientes e o hospital, visando garantir eficiência e transparência em suas relações.

É indispensável que as instituições que passam por processo avaliativo realizado pelos clientes estejam preparadas para corrigir e modificar as não conformidades de seus serviços com base no resultado da avaliação. Do contrário, esse processo fornecerá apenas informações sobre a insatisfação do cliente, sem uma condução para a resolutividade.

Percebe-se que algumas demandas identificadas como pontos de insatisfação dos clientes com o HSCSL eram referentes ao tempo de espera para o atendimento, agilidade e presteza nas informações, desde a internação até a alta. Com a investigação realizada com o Serviço de Ouvidoria do hospital, constatou-se, no geral, que desde a implantação dos ciclos de melhorias (treinamentos desenvolvidos pelo Setor de $\mathrm{RH}$, atuação do psicossocial no pronto atendimento, visita nas unidades pelo serviço de Ouvidoria etc.) os clientes estão satisfeitos com a qualidade do serviço prestado pela instituição. Destaca-se como ponto positivo evidenciado o feedback que a Ouvidoria repassa aos setores quando elogiados, prática essa favorável ao fortalecimento das atividades e à autoestima das equipes.

Garantir um atendimento de excelência nos serviços prestados é importante para que as instituições criem um relacionamento com os clientes, daí a relevância de um canal que possa avaliar sua satisfação e insatisfação e no qual essas informações sejam usadas, posteriormente, para a melhoria contínua dos processos.

\section{REFERÊNCIAS}

AGÊNCIA NACIONAL DE VIGILÂNCIA SANITÁRIA. Manual Brasileiro de Acreditação: das organizações prestadoras de serviços de saúde. Brasília: Organização Nacional de Acreditação, 2018.

ALVES JUNIOR, M. N. Garantindo a efetividade das Ouvidorias. Dissertação. Disponível em: http://www.omd.com. br. Acesso em: 19 maio 2018.

BURMESTER, H. et al. Manual de Gestão Hospitalar do CQH. 2. ed. São Paulo: Yendis Editora, 2009.

CANCLINI, N. G. Consumidores e cidadãos: conflitos multiculturais da globalização. 8. ed. Rio de Janeiro: Editora UFRJ, 2010.

COUTO, R. C; PEDROSA, T. M. G. Hospital: Acreditação e Gestão em Saúde. Rio de Janeiro: Guanabara Koogan, 2007.

GIL, C. Métodos e técnicas de pesquisa social. 5. ed. São Paulo: Atlas, 1999.

GODOI, A. F. Hotelaria Hospitalar: Humanização no Atendimento Hospitalar. 2. ed. São Paulo: Ícone, 2008.

KOTLER, Philip. Administração de Marketing: análise, planejamento, implementação e controle. 6. ed. São Paulo: Atlas, 1998.

LUONGO, J. et al. Gestão de qualidade em saúde. 1. ed. São Paulo: Rideel, 2011. 
MANZO. B. F. O processo de acreditação hospitalar na perspectiva de profissionais de saúde. Dissertação (mestrado em enfermagem) - Escola de Enfermagem da Universidade Federal de Minas Gerais, Belo Horizonte, 2009.

NOGUEIRA, L. C. L. Gerenciando pela qualidade total na saúde. 3. ed. Nova Lima: INDG Tecnologia e Serviços Ltda., 2008.

PESSINI, L.; GIANELLA JÚNIOR, F. G. (Org.). Missões camilianas na foz do rio Amazonas. São Paulo: Centro Universitário São Camilo, Província Camiliana Brasileira, 2012. 